\section{Cypriot Journal of Educational Sciences}

Volume 17, Issue 2, (2022) 664-675

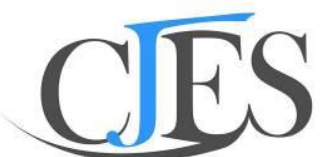

Cypriot Joumal of Educational Sciences

\title{
Forming environmental competence in future biology teachers through project tasks
}

Arailym Amantayeva ${ }^{1}$, Abai Kazakh National Pedagogical University, Institute of Natural Sciences and Geography, Address: 13, Dostyk ave, 050010, Almaty City, Kazakhstan https://orcid.org/0000-0001-8053-5900

Sholpan Karbayeva 2, Abai Kazakh National Pedagogical University, Institute of Natural Sciences and Geography. Address: 13, Dostyk ave, 050010, Almaty City, Kazakhstan https://orcid.org/0000-0001-8581-6460

Zhumadil Childibayev ${ }^{3}$, Abai Kazakh National Pedagogical University, Institute of Natural Sciences and Geography, Address: 13, Dostyk ave, 050010, Almaty City, Kazakhstan

Gulzhazira Turlybekova ${ }^{4}$, Academician Y.A.Buketov Karaganda University, Biology-geography faculty. Address: 231apt., 43, Lobody Street, 100008, Karaganda city, Kazakhstan

Gani Issayev 5, Techn. candidate of science, Khoja Ahmed Yasawi International Kazakh-Turkish university, , Address: 29, B. Sattarkhanov Street, 161200, Turkestan, Kazakhstan https://orcid.org/0000-0002-5979-8278.

Petr Stankevich ${ }^{6}$, Herzen State Pedagogical University of Russia, Social Security Faculty, Address: 48, Moika Embankment, 191186, St.Petersburg, Russia. https://orcid.org/0000-0001-6506-7968

\section{Suggested Citation:}

Amantayeva, A., Karbayeva, S., Childibayev, Z., Turlybekova, G., Issayev, G., \& Stankevich, P., (2022). Forming environmental competence in future biology teachers through project tasks. Cypriot Journal of Educational Science. 17(2),664-675. https://doi.org/10.18844/cjes.v17i2.6863

Received from August 16, 2021; revised from October 25, 2021; accepted from February 15, 2022.

(C)2022 Birlesik Dunya Yenilik Arastirma ve Yayincilik Merkezi. All rights reserved.

\begin{abstract}
The impact of human economic activities on individual natural components or whole geosystems has caused a global environmental crisis and continues to change the surface of the planet beyond recognition. New biospheric thinking is required to overcome the existing threats. For that purpose, the new generation shall possess high ecological culture. The article aimed to examine the problem of formation and development of environmental competence of students based on project technology. The conducted research allowed students to independently identify environmental problems with the help of project technology. Practical development in the form of project tasks contributes to the formation of environmental competence in future biology teachers. The effectiveness of the proposed training technology is confirmed by the results of experimental work.
\end{abstract}

Keywords: environmental awareness; environmental competence; environmental education; didactic conditions; project tasks.

\footnotetext{
* ADDRESS FOR CORRESPONDENCE: Name, Arailym Amantayeva, Abai Kazakh National Pedagogical University, Institute of Natural Sciences and Geography, Address: 13, Dostyk ave, 050010, Almaty City, Kazakhstan.

E-mail address: araika2190@mail.ru
} 
Amantayeva, A., Karbayeva, S., Childibayev, Z., Turlybekova, G., Issayev, G., \& Stankevich, P., (2022). Forming environmental competence in future biology teachers through project tasks. Cypriot Journal of Educational Science. 17(2),664-675. https://doi.org/10.18844/cjes.v17i2.6863

\section{Introduction}

The content of biological education envisages the approximation of the training process and the actual professional activity in the course of the study (Ferdosipour \& Mirzaei, 2021). The requirements imposed by society to a future teacher of biology urge the need to update the program of education of future teachers. Future biology teachers should possess certain competencies and be capable of creative activity.

Improvement of the professional level of teachers is an important part of the state educational policy of Kazakhstan, as noted by the Head of State Kassym-Zhomart Tokayev in his Address to the people of Kazakhstan "A New Stage of Social Modernization." The Head of the State paid special attention to the social sphere and tasked the pedagogical society to improve the quality of education (Nur-Sultan,2019). To face modern challenges, the state needs creatively working teachers with a high level of professional knowledge and skills. The main skill is the knowledge of the scientific foundations of the subject they teach and the relevant teaching methods.

The modernization of the content of biological training in modern pedagogical universities is focused on the actualization of the value potential for personal development. The modernization includes the development of conceptual integrative models of the content of biological education, taking into account the achievements in Biology, Pedagogy, Philosophy, Ecology, etc. Today, new pedagogical approaches to teaching Biology are required (Educational program, 2020a; 2020b; 2020c). The traditional ways of delivering the subject knowledge do not ensure achieving the objectives of teaching Biology. Therefore, the modern educational system should look for non-traditional forms of teaching.

The State Compulsory Education Standards of the Republic of Kazakhstan have been the basis for developing curricula for various disciplines at all higher education levels, including Bachelor, Master, and Ph.D. New curricula set high standards of quality of higher education. They are oriented on the expected personal, meta disciplinary, and disciplinary learning outcomes. A new purpose, content, methods, and a new informational and educational environment are required to achieve the expected training results. Today, the level of mastering the curricula is a key characteristic of the quality of education. Mastering the competencies, which are the generalized methods of actions, or the achievement of new levels of development of students' personalities, become the main learning outcomes.

\subsection{Literature review}

Consumer attitude towards the environment and natural resources contributes to the aggravation of the global environmental crisis. Ecological and economic stability are required to overcome the environmental crisis and achieve harmony with the biosphere. The educational system must be given reasonable and realistic goals. The development of global ecological consciousness is one of the main drivers of a positive change in the existing reality.

Environmental consciousness is a set of ideas about the man-nature system's relations. Environmental consciousness is based on understanding the negative consequences of environmental neglect (Kelkay \& Endris, 2020). The content of environmental consciousness is revealed through the concepts of "environmental relations" and "environmental activity." American psychologist of the XXth century Gibson proposed the structure of the environmental perception of the world based on 
Amantayeva, A., Karbayeva, S., Childibayev, Z., Turlybekova, G., Issayev, G., \& Stankevich, P., (2022). Forming environmental competence in future biology teachers through project tasks. Cypriot Journal of Educational Science. 17(2),664-675. https://doi.org/10.18844/cjes.v17i2.6863

the idea that a man lives and acts in an environmental world (Baranov \& Sharafutdinov, 2017). Today, this idea is the theoretical and methodological basis of global environmental awareness.

The driving forces of the process of developing environmental competence are the resolution of environmental contradictions, for example, between the desire of a person to live in an environmentally more favorable, safe environment and the lack of conditions and opportunities for this. Such contradictions are resolved in environmental activities, the object, subject, and content of which, presented as components of the content of education, determine environmental competence. The relationship of environmental competence with other categories of environmental psychology and pedagogy suggests the following logic. Environmental knowledge acquired by students in the process of environmental education, environmental ideas formed in everyday life, contribute to awareness of the importance of environmental problems, understanding the value of nature (Tilbury, 2004). Knowledge and values influence the formation of ecological consciousness, are transformed into beliefs that lay the foundation for an ecological worldview. In turn, the worldview determines the ideals of the individual, determines the attitude to nature, which are manifested in environmental activities - actions, deeds, behavior, habits.

In other words, ecological behavior is a consequence of the realization of the content of ecological consciousness. That is why the formation of environmental competence is extremely important, and every subject can and should solve this problem. From a methodological point of view, the development and implementation of educational projects by students aimed at improving the state of the environment in the process of identifying, studying, solving, and preventing environmental problems is an adequate tool for the formation of environmental competence (Sanchez-Muñoz et al., 2020).

The environmental competence and professional readiness of future biology teachers to solve the tasks of environmental education should advance beyond. The environmental competencies of future biology teachers are described in the following content lines:

- knowledge of environmental laws, rules, theories, scientific facts;

- the emotional, aesthetic, and moral perception of nature;

- acting in real social and natural situations related to solving environmental problems (Sadykova \& Niyazova, 2014).

Therefore, pedagogical universities shall deliver a certain amount of knowledge in Ecology and facilitate acquiring competencies in the scientific analysis of natural phenomena, understanding the society-nature interaction, and realizing the importance of practical support to nature.

The effectiveness of environmental education can be ensured by including in the learning processes such forms and methods that put students in the position of researchers and discoverers. In this regard, the project method is particularly promising. For a clearer understanding of the concept of "project method", we will analyze the concept of the project. A project is a set of certain actions, documents, preliminary texts, a plan for creating a real object, an object, creating a different kind of theoretical product. A project is a creative activity. The method of projects in the system is considered as one of the training options (an alternative to the class-based system at school, lectures with a university) (Li et al, 2010).

A modern project is a didactic tool for activating cognitive activity, developing creativity, and forming student competencies, including environmental ones (Vokhmentseva, 2011). Thus, under the concept of "project method," we can understand a pedagogical method (technology) aimed at acquiring new information and applying it, and not just integrating actual knowledge. 
Amantayeva, A., Karbayeva, S., Childibayev, Z., Turlybekova, G., Issayev, G., \& Stankevich, P., (2022). Forming environmental competence in future biology teachers through project tasks. Cypriot Journal of Educational Science. 17(2),664-675. https://doi.org/10.18844/cjes.v17i2.6863

Independent work of students in the course "Ecology and Sustainable Development» is based on the principle of students' consciousness and activity, with the advisory and supervising function of the teacher. The system of project tasks supports the formation of professional abilities and skills needed to implement the main functions of a biology teacher. Independent activity opens up the possibility for individually differentiated and personality-oriented approaches when assigning tasks of different degrees of complexity. Project tasks involve students in the training, research, and creative activity in the theory and practice of teaching Ecology.

Project tasks are the highest form of training research that contains all the scientific research elements, from posing a problem to summarizing the results obtained and drawing conclusions and recommendations. At that, the developing personality and individuality of a future specialist become the logical center of the pedagogical process (Sharafutdinov, 2012; Shumakova \& Sevostyanova, 2018).

\subsection{Purpose of study}

Several researchers have proven the necessity and relevance of project tasks in the updated content of education and reviewed different ways of formation of project tasks (Yakimanskaya, 2000). For instance, Yakimanskaya found the successful formation of project skills to be associated with the mastery of mental operations (analysis and synthesis, abstraction, and specification). Analysis, synthesis, abstraction, and concretization are required to form the environmental competence of a future biology teacher. This article aimed to examine the problem of formation and development of environmental competence of students based on project technology.

\section{Methods}

To solve specific tasks of forming students ' ecological competence, we used the model of forming ecological competence. In which information and cognitive (general education and educational tasks in the field of ecology are solved), operational and activity (environmental skills are formed), and practice-oriented (environmental consciousness of the individual is formed, which determines its civic position) levels are considered.Thus, based on the obtained data, we propose to use the three most significant criteria for assessing the level of environmental competence: valuemotivational, cognitive, and activity-practical.The formation of such qualities in students is especially effective in the process of independent activity based on project tasks.

In conducting the study, the following research methods were used:

1. Theoretical: analysis of psychological and pedagogical, scientific and methodological and educational literature, materials of scientific and practical conferences; study of the experience of teachers; modeling of the teacher's activity on the formation of environmental competence of students in the process of project implementation.

2. Empirical: pedagogical observation, testing, experimental search work.

\section{Results}

We have developed criteria for the algorithm of project tasks for the formation of the environmental competence of a future biology teacher:

1. The formation of educational and cognitive interest in students (identification of causal relationships by the students; students' questions; the students' desire to exchange interesting facts and scientific data with the teachers; the students' ability to generalize and make independent conclusions, etc.). The educational and cognitive interest of students is dependent on the specifics of 
Amantayeva, A., Karbayeva, S., Childibayev, Z., Turlybekova, G., Issayev, G., \& Stankevich, P., (2022). Forming environmental competence in future biology teachers through project tasks. Cypriot Journal of Educational Science. 17(2),664-675. https://doi.org/10.18844/cjes.v17i2.6863

personality-centered education. The teacher makes interpretations in the context of students' motivation and personal position.

2. The content of educational activities on the formation of project skills (mastering training material and solving training tasks; general methods of action and scientific concepts, etc.). The teacher transforms the training material, adapts it to the learning capacity of students, etc.

3. The degree of project skills' mastering (mastering an element of the project activity results in the formation of a corresponding specific skill). A student has to study new material, develop specific skills to master an element of project activity.

4. The formation of the environmental competence of a future biology teacher using the project method as one of the pedagogical technologies. This method is based on expanding and enriching the student's individual experience through practical activity. The project method includes the active use of pedagogical technologies to implement a number of the most important theoretical provisions of the concept of environmental education for sustainable development.

Project tasks that form the motivation to obtain project skills include advanced tasks, tasks with a missing condition, and tasks that put the student in a choice situation (Serikov, 1999). Advanced tasks develop readiness for self-education and contribute to reaching the developmental goals of the student's independent cognitive activity. Independent search for information in different sources contributes to developing mental operations such as comparison, proof, analysis, and synthesis. Advanced tasks are selected by the teacher and require different student activities (intellectual, design, modeling, etc.). Advanced tasks require working with non-traditional sources (periodicals, Internet resources), collecting and processing data, systematizing it, and preparing a script.

Solving tasks with a missing condition, students master self-control and mutual control, develop the ability to discuss, determine missing information in the text of the task, see the alternatives in the problem situation, search for the necessary information in various sources, reveal contradictions, navigate an excessive amount of information, etc. (Ivanov, 2000; Zorkina, 2011). Tasks that put the student in a choice situation include training, research, or applied projects. Educational projects are specific tasks on studying a topic and are combined with laboratory and practical work. Research or applied projects are the main communication forms between students and professional scientists, biologists, and ecologists to attract the general population to solve environmental problems.

Project tasks are of great importance in the training process. They develop the value attitude of students to basic knowledge and support the formation of corresponding skills. Independent fulfillment of project tasks forms project skills in students (Tsybulsky et al., 2018). The learning activity aimed to form project skills includes solving subject-cognitive tasks and practice-oriented tasks. Subject-cognitive tasks imply processing the studied material (the ability to explain causal patterns, generalize concepts, phenomena, etc.). Practice-oriented tasks are focused on using the acquired theoretical knowledge in practice (application of theory in a familiar situation, transformation, design, comparison, planning, optimization, etc.). Project tasks are actively used in practical training as they promote creative, active mastery of knowledge in the context of personal development and provide ways for the practical implementation of the acquired knowledge.

Following the requirements of the State Compulsory Higher Education Standard of the Republic of Kazakhstan, the content of environmental competence can be presented as follows:

- creating favorable conditions for all living things, preservation of their life and health;

- cognition of nature to harmoniously integrate your activities in the natural processes;

- spiritual connection to nature, the desire to see and realize the beauty of the surrounding world, to preserve and protect it; 
Amantayeva, A., Karbayeva, S., Childibayev, Z., Turlybekova, G., Issayev, G., \& Stankevich, P., (2022). Forming environmental competence in future biology teachers through project tasks. Cypriot Journal of Educational Science. 17(2),664-675. https://doi.org/10.18844/cjes.v17i2.6863

- the desire to understand your role and purpose in the world, the meaning of your life, and to design your activities accordingly;

- seeing a holistic picture of global ecology, explaining connections and dependencies in ecosystems;

- the ability to apply environmental knowledge practically to identify, solve and prevent environmental problems;

- taking part in the development and implementation of environmental education projects aimed at improving the state of the environment;

- mastering the techniques and methods of environmentally friendly life, the formation of values towards nature, personal environmental activities.

These components of environmental competence were the basis to develop didactic conditions for the formation of environmental competence of future biology teachers to determine the effectiveness of the research made:

1. The development of project tasks with environmental content to be used in teaching the subject "Ecology and Sustainable Development": the clarification of objectives, principles of selecting the curricula content, and the use of methods, forms, and teaching aids that promote the formation of environmental competence of future biology teachers. The project tasks integrate specific environmental terms familiar to students. Both teachers and students participated in developing the project tasks.

2. Structuring the content of teaching aimed at the formation of project skills that would ensure the implementation of educational and cognitive activities, taking into account the optimal correspondence of the course structure to developing environmental literacy.

3. Building interdisciplinary connections and using methodological techniques that contribute to mastering the project skills by students (statement of the problem, posing problematic questions using the content of other subjects, modeling, educational research, demonstration of problem-solving, working with software, etc.)

Most researchers (Pavlov \& Bazhenova, 2012; Shumakova et al.,2018; Tsybulsky et al., 2018) distinguish the following stages of project training: development of the project task; project implementation; design of results; presentation and defense of the project; reflection; Work begins with the fact that the teacher together with the student (or a small group of students) discusses the project task - the goal, tasks, and problem that the student needs to solve is set. The main activities of the teacher and students in project training are presented in Table 1.

\section{Table 1}

Systems of actions of the teacher and students at different stages of work on the project

\begin{tabular}{|c|c|c|}
\hline Stages & Teacher's activity & The activities of the students \\
\hline \multicolumn{3}{|l|}{ 1. Development of the project task } \\
\hline \multirow[t]{2}{*}{ 1.1. Choosing a project topic } & $\begin{array}{l}\text { Selects possible topics and offers them to } \\
\text { students. } \\
\text { Invites students to jointly select } \\
\text { (formulate) the topic of the project. }\end{array}$ & $\begin{array}{l}\text { Discuss and make a general decision on } \\
\text { the topic. } \\
\text { A group of students together with the } \\
\text { teacher selects topics and offers them } \\
\text { for discussion. }\end{array}$ \\
\hline & $\begin{array}{l}\text { Participates in the discussion of topics } \\
\text { proposed by students. }\end{array}$ & $\begin{array}{l}\text { They independently select topics and } \\
\text { offer them to the group for discussion. }\end{array}$ \\
\hline $\begin{array}{l}\text { 1.2. Highlighting sub-topics in the } \\
\text { project topic }\end{array}$ & $\begin{array}{l}\text { Pre-selects subtopics and offers students } \\
\text { to choose from. }\end{array}$ & $\begin{array}{l}\text { Each student chooses a sub-topic or } \\
\text { suggests a new one. }\end{array}$ \\
\hline
\end{tabular}


Amantayeva, A., Karbayeva, S., Childibayev, Z., Turlybekova, G., Issayev, G., \& Stankevich, P., (2022). Forming environmental competence in future biology teachers through project tasks. Cypriot Journal of Educational Science. 17(2),664-675. https://doi.org/10.18844/cjes.v17i2.6863

\begin{tabular}{|c|c|c|}
\hline & $\begin{array}{l}\text { Participates in the discussion with } \\
\text { students of the sub-topics of the project. }\end{array}$ & $\begin{array}{l}\text { Actively discuss and offer options for } \\
\text { sub-topics. Everyone chooses one of } \\
\text { them for themselves (that is, they } \\
\text { choose a role for themselves). }\end{array}$ \\
\hline 1.3. Formation of creative groups & $\begin{array}{l}\text { Conducts organizational work to unite } \\
\text { students who have chosen specific } \\
\text { subtopics and activities. }\end{array}$ & $\begin{array}{l}\text { They define their roles and are grouped } \\
\text { according to them into small teams. }\end{array}$ \\
\hline $\begin{array}{l}\text { 1.4. Preparation of materials for } \\
\text { research work: } \\
\text { formulation of questions to be } \\
\text { answered, the task for groups, } \\
\text { selection of literature }\end{array}$ & $\begin{array}{l}\text { If the project is large, the teacher } \\
\text { develops tasks, questions for search } \\
\text { activities and literature in advance }\end{array}$ & $\begin{array}{l}\text { Individual students take part in the ' } \\
\text { development of tasks. } \\
\text { Questions to find the answer can be } \\
\text { developed in teams, followed by } \\
\text { discussion in groups. }\end{array}$ \\
\hline $\begin{array}{l}\text { 1.5. Definition of the forms of } \\
\text { expression of the results of project } \\
\text { activities }\end{array}$ & Takes part in the discussion. & $\begin{array}{l}\text { Students in groups, and then all } \\
\text { together discuss the forms of } \\
\text { presentation of the result of research } \\
\text { activities: video, album, natural objects, } \\
\text { literary living room, etc. }\end{array}$ \\
\hline 2. Project development & $\begin{array}{l}\text { Advises coordinates the work of } \\
\text { students, stimulates their activities. }\end{array}$ & They carry out search activities. \\
\hline 3. Design of the result & $\begin{array}{l}\text { Advises coordinates the work of } \\
\text { students, stimulates their activities. }\end{array}$ & $\begin{array}{l}\text { First, by groups, and then in } \\
\text { cooperation with other groups, they } \\
\text { formalize the results }\end{array}$ \\
\hline 4. Presentation & $\begin{array}{l}\text { Examination (invites as experts of } \\
\text { students from other groups, parents, } \\
\text { etc.). }\end{array}$ & $\begin{array}{l}\text { They report on the results of their } \\
\text { work. }\end{array}$ \\
\hline 5. Reflection & & $\begin{array}{l}\text { They reflect on the process, themselves } \\
\text { in it, taking into account the } \\
\text { assessment of others. }\end{array}$ \\
\hline
\end{tabular}

With this logic of the educational process, the student together with the teacher "creates the world". In addition to the logical scheme of analysis of the surrounding world adopted in the traditional teaching system, a synthesis scheme is added, which is implemented in various forms: from the simple execution of reproductive, partially search tasks of the teacher to the independent implementation of a research project. We compiled an algorithm to identify the initial level of environmental competence of future biology teachers:

- determination of main research purposes;

- description of the problem situation;

- preliminary analysis of the problem situation.

The initial level of environmental competence of future biology teachers was diagnosed to validate the research results (Table 2 ).

Table 2

Validation of research results

\begin{tabular}{ll}
\hline \multicolumn{1}{c}{ Components of environmental competence } & \multicolumn{1}{c}{ Plausibility check methods } \\
\hline Theoretical knowledge & oral, written, and test tasks \\
$\begin{array}{l}\text { Environmental competencies (practical skills, } \\
\text { abilities) }\end{array}$ & questionnaires, pedagogical observation, practical \\
(project) tasks, etc.
\end{tabular}

At the final stage, we studied and analyzed the real situation of building the learning process of the elective course "Ecology and Sustainable Development", which has developed in the practice of working with students of Abai KazNPU and Atyrau State University named after Kh.Dosmukhamedov. To identify the initial level of formation of students ' environmental competence, the following 
Amantayeva, A., Karbayeva, S., Childibayev, Z., Turlybekova, G., Issayev, G., \& Stankevich, P., (2022). Forming environmental competence in future biology teachers through project tasks. Cypriot Journal of Educational Science. 17(2),664-675. https://doi.org/10.18844/cjes.v17i2.6863

methods were used: a written survey, a questionnaire, and filling out self-diagnosis sheets; the test "Environmental culture" was conducted.

The analysis of checking the initial state of environmental competence formation indicates the predominance of subject-cognitive tasks. Indicators of project tasks aimed at applying the acquired knowledge in practice and directly at developing project skills showed a low level (Figure 1).

Figure 1

The initial state of environmental competence formation among students of KazNPU Abaya and Atyrau State University was named after Kh.Dosmukhamedov

Subject-cognitive tasks

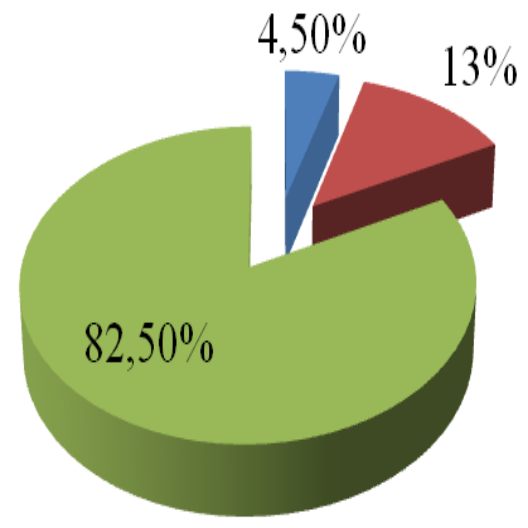

Project tasks

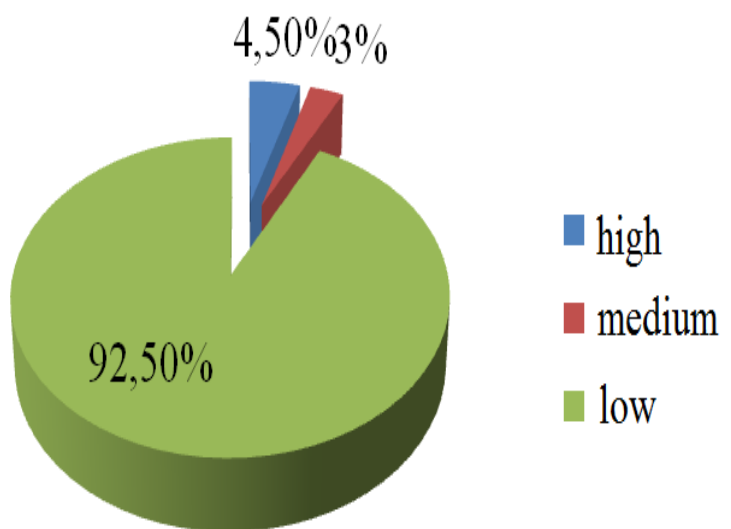

From Figure 1, we can see that the level of environmental competence before the experiment is very low. Accordingly, based on the obtained analytical data, at the beginning of the 2018-2019 academic year, a group of 1st - year students in the specialty 6B01515-Biology were offered a choice of topics for environmental projects based on subject-cognitive and project tasks (Table 3,4). Verification of the initial and final states was carried out at the beginning and end of the academic year when students attended the course "Ecology and Sustainable Development" of the component for the selection of the cycle of profile disciplines.

Table 3

Diagnostics of the level of formation of environmental competence on subject-cognitive tasks.

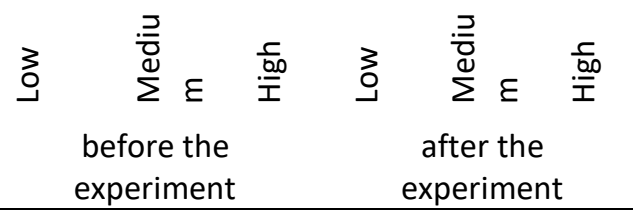


Amantayeva, A., Karbayeva, S., Childibayev, Z., Turlybekova, G., Issayev, G., \& Stankevich, P., (2022). Forming environmental competence in future biology teachers through project tasks. Cypriot Journal of Educational Science. 17(2),664-675. https://doi.org/10.18844/cjes.v17i2.6863

1. The role of ecology in the life of modern society.

2. Common patterns of the impact of environmental factors on living organisms.

Abai Kazakh National Pedagogical University (100 humans)

3. Differences between the concepts of "habitat" and "ecological niche."

4. Types of environmental interactions. 5. Similarities and differences between the concepts of "ecosystem,"

"biogeocenosis," and "biosphere."

6. Ecosystem organization patterns.

7. Ecological succession, etc.
Kh.DosmukhamedovAt yrau State University

(100 humans)

80

17

3

12

32

56

Table 4

Diagnostics of the level of formation of environmental competence for project tasks

Project Tasks University, students

Level of environmental competence

formation

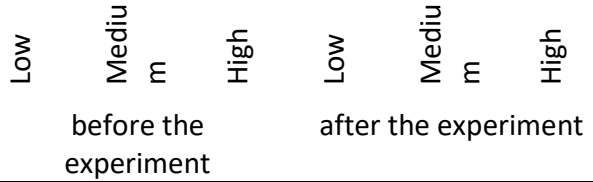

1. How do the main ideas of the concept of sustainable development of society apply to children and youth public associations' activities?

Abai Kazakh National

Pedagogical University (100 humans)

2. What are the goals of the social-ecological movement?

3. What are the main approaches and methods of activities of children and youth public organizations?

4. You are the leader of a children's environmental organization. How can you impact the implementation of the concept of sustainable development of society?

Comparing the data obtained on the subject-cognitive and project tasks, it can be concluded that at the end of the experimental search work, students who performed tasks on the subjectcognitive have $50.5 \%$ and in the project tasks $75 \%$ of indicators of high levels of formation of environmental competence. Also, other students showed interest in the implementation of projects in the future. This allows us to speak about the effectiveness of the developed methodology (Figure 2).

\section{Figure 2}

Indicators of the formation of environmental competence among students of Abai KazNPU and Atyrau State University named after Kh.Dosmukhamedov. 


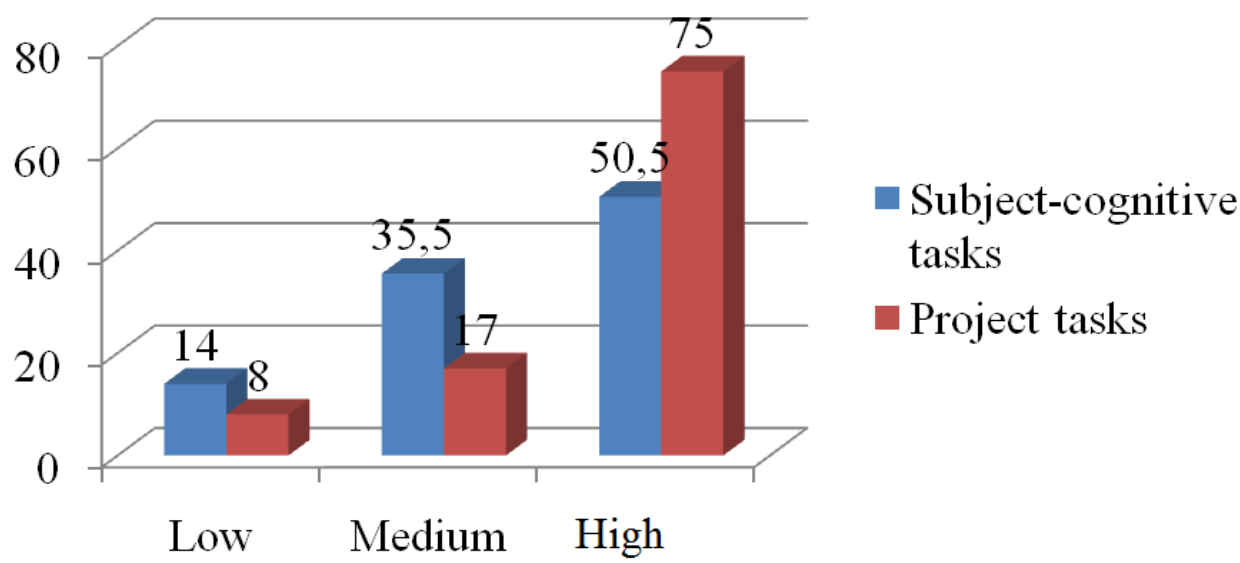

Thus, the verification of the reliability of research results at the end of the first course allows us to state the following:

- students show the highest results in terms of project tasks;

- application of theoretical knowledge in practice students showed weak results.

The developed educational programs are practice-oriented, in this regard, the purpose, content, methods, and information, and educational environment, in general, have been changed in the educational program.

\section{Discussion}

The task of a teacher in modern conditions is to educate an active, creative person who can conduct an independent search, make his discoveries, solve emerging problems, make decisions, and bear responsibility for them, i.e., the formation of competencies. The formation of environmental competence should become an integral part of all educational work. Today, the natural sciences program devotes very little time to study the environmental aspects of various technogenic processes. In addition, the lesson has its own "hard" framework: its goals, objectives, and content. In this regard, such important components of ecological culture as value orientations, a system of norms and rules concerning nature, and, especially, practical skills for studying and preserving the environment, remain unfulfilled (Kelkay \& Sitotaw, 2019). As a result, the formation of the environmental competence of students remains difficult to achieve. One of the means of solving this problem is project activity. As such, we have considered the concept of environmental competence and identified didactic elements that are part of the structural component of environmental competence.

We studied the classification of projects and the stages of activity of the teacher and students during the implementation of project activities. Of course, the most problematic aspect of the teacher's work is the choice of the topic for the project of environmental orientation. The result is that students have increased their knowledge of hazards that threaten the safety of the environment and human health. Also, they have an interest in performing more complex projects (Jahangard et al., 2020; Uaidullakyzy, 2020; Ghezir et al., 2021).

As a result, we came to the conclusion that the implementation of projects increases students' motivation and interest in learning, provides a deeper understanding of the topic being studied, and forms practical experience. And the choice of environmental topics allows students to form a careful 
Amantayeva, A., Karbayeva, S., Childibayev, Z., Turlybekova, G., Issayev, G., \& Stankevich, P., (2022). Forming environmental competence in future biology teachers through project tasks. Cypriot Journal of Educational Science. 17(2),664-675. https://doi.org/10.18844/cjes.v17i2.6863

attitude to the surrounding nature and makes them think about serious environmental problems that exist in the world.

\section{Conclusion}

A conversation with a group of students allowed us to jointly conclude that the implementation of the project is complex but interesting work. In the future, they would like to try more complex projects. Also, other students of parallel groups who observed the project showed interest in the implementation of the projects. The project-based approach to learning is characterized by its local uniqueness. The proposed topics are usually closely related to the surrounding environment and community. Students ' interests can be aroused and maintained.

Students who participated in this project noted that their learning motivation was enhanced. They were actively involved in relevant activities outside of classes. This project also opens up opportunities for other scientific research. Some students began planning further studies and careers in environmental protection or other environmental issues. In particular, most of the participating students studied environmental sciences or a related field, most said that this was their first experience of the importance of nature conservation.

\section{Acknowledgment}

We thank all the students who participated in this study, filled out the questionnaire, and shared their beliefs and opinions about this pedagogical approach.

\section{References}

Baranov, A. \& Sharafutdinov, R. (2017). Formation and development of environmental competence in the future technology teacher on the basis of problem-based project training. Bulletin of the Udmurt University. Series " Philosophy. Psychology. Pedagogy", 4(27), 483-490. https://journals.udsu.ru/philosophy-psychology-pedagogy/article/view/840

Educational program (2020'a). 6B01515-Biology. Approved by the Scientific Council of the KazNPU named after Abaya, protocol №12 from «10» august 2020.

Educational program (2020b). 7M01515-Biology. Approved by the Scientific Council of the KazNPU named after Abaya, protocol № 13«10» august 2020.

Educational program (2020c). 8D01515-Biology. Approved by the Scientific Council of the KazNPU named after Abaya, protocol № 14 «10» august 2020.

Ferdosipour, A., \& Mirzaei, Z. (2021). The effectiveness of preventive-behavioural therapy and cognitive anxiety group and student's attention. Global Journal of Psychology Research: New Trends and Issues, 11(2), 89102. https://doi.org/10.18844/gipr.v11i2.5303

Ghezir, S. ., Naimie, Z. ., Leng, C. H., Shagholi, R. ., \& Abuzaid, R. A. . (2021). Review study: Competency-based approach implementation in educational system. New Trends and Issues Proceedings on Humanities and Social Sciences, 8(3), 21-29. https://doi.org/10.18844/prosoc.v8i2.6156

Ivanov, V. (2000). Anticipatory tasks as a way of managing independent cognitive activity of cadets of military educational institutions: author's thesis-Saratov. 187 p. https://elibrary.ru/item.asp?id=15987255

Jahangard, A., Rahimi, A., \& Norouzizadeh, M. (2020). Student attitudes towards computer-assisted language learning and its effect on their EFL writing. International Journal of New Trends in Social Sciences, 4(1), 01-09. https://doi.org/10.18844/ijntss.v4i1.4785 
Amantayeva, A., Karbayeva, S., Childibayev, Z., Turlybekova, G., Issayev, G., \& Stankevich, P., (2022). Forming environmental competence in future biology teachers through project tasks. Cypriot Journal of Educational Science. 17(2),664-675. https://doi.org/10.18844/cjes.v17i2.6863

Kelkay, A. D., \& Endris, A. (2020). Model-based instruction to improve the concept of students on human anatomy: Primary School, Ethiopia. International Journal of Learning and Teaching, 12(2), 72-85. https://doi.org/10.18844/ijlt.v12i2.4618

Kelkay, A. D., \& Sitotaw, C. (2019). The effect of practical work to enhance ninth-grade achievement in biology class: The case of diaspora secondary school, Ethiopia. Global Journal of Guidance and Counseling in Schools: Current Perspectives, 9(3), 95-105. https://doi.org/10.18844/gigc.v9i3.4253

Li, H.C., Du, X.Y., Stojcevski, A., \& Benz, T., (2010). Innovation and PBL Implementation in Higher Education e Approaches for Educational Chang to PBL. London Science Publishing Limited, London. https://vbn.aau.dk/en/publications/innovation-and-pbl-implementation-in-higher-educationapproaches-

Nur-Sultan, (2019). Akorda Message of the Head of State to the people of Kazakhstan.

Pavlov, S., \& Bazhenova K. A. (2012). Statement of the research problem in education. Concept. 12. URL: http://www.covenok.ru/koncept/2012/12170.htm. (Date of request: 27.10.2019)

Sadykova, E., \& Niyazova, A. (2014). Formation of ecological competencies in the process of training future teachers. Fundamental research, 9(11), 2066-2069. https://fundamentalresearch.ru/ru/article/view?id=35897

Sanchez-Muñoz, R., Carrió, M., Rodríguez, G., Pérez, N., \& Moyano, E. (2020). A hybrid strategy to develop reallife competences combining flipped classroom, jigsaw method, and project-based learning. Journal of Biological Education, 1-12., https://doi.org/10.1080/00219266.2020.1858928

Serikov, V. (1999). Paradigm of modern education: orientation to personality. Scientific and pedagogical schools of the South of Russia: theory and history of development. Release - 2. - Access: http://edu.donpac.ru.

Sharafutdinov, R. (2012). Problem-project-based learning in the training of teachers: textbook. Izhevsk: Udmurt State University, $\quad$ 9-23. http://94.25.116.179/xmlui/bitstream/handle/123456789/8601/201220.pdf?sequence=

Shumakova, E. O., \& Sevostyanova, S. A. (2018). Formation of design skills in educational projects of bachelors in specialized mathematical disciplines. Modern problems of science and education, (5), 195-195. https://elibrary.ru/item.asp?id=36367983

Tilbury, D. (2004). Environmental education for sustainability: a force for change in higher education. Higher education and the challenge of sustainability: problematic, promise, and practice. Editor/Peter Blaze Corcoran; Arjen E. J Wals. Dordrecht, The Netherlands: Kluwer Academic Publishers (pp. 97-112). https://link.springer.com/content/pdf/10.1007/0-306-48515-X 9.pdf

Tsybulsky D., Dodick J., \& Camhi J. (2018). High-school students in university research labs? Implementing an outreach model based on the 'science as inquiry' approach, Journal of Biological Education, 52(4), 415428. DOI: $10.1080 / 00219266.2017 .1403360$

Uaidullakyzy, E. (2021). Formation of information and professional competence of primary school teachers with Online Education. World Journal on Educational Technology: Current Issues, 13(4), 838-850. https://doi.org/10.18844/wjet.v13i4.6269

Vokhmentseva, E. (2011). Project activity of students as a means of forming key competencies. Actual tasks of pedagogy: materials of the International Scientific Conference, Chita: Young Scientist Publishing House, 65. https://link.springer.com/chapter/10.1007/978-3-030-77291-8 34

Yakimanskaya, I. (2000). Technology of personality-oriented education, M.: September, - Release.7. http://childpsy.ru/lib/books/id/8298.php

Zorkina, N. (2011). Application of means of advanced training in the assimilation of basic concepts of educational activity. Teacher XXI century, 1, 64-70. 